\title{
Cómo indagar cuando el ojo se salta el muro
}

\section{Como perguntar quando o olho atravessa o muro}

How to inquire when the eye jumps the wall

\author{
Ramón Cabrera-Salort \\ casalort@cubarte.cult.cu \\ Instituto Superior de Arte (ISA), La Habana
}

\section{RESUMEN}

Una revisión del estado actual del conocimiento sobre las capacidades de investigación en Educación Artística y sus relaciones con la práctica

Palabras-clave: Educación Artística; Investigación educativa

\section{RESUMO}

Este artigo apresenta uma revisão sobre o estado atual do conhecimento sobre as capacidades de investigação em Educação Artística e das suas relações com a prática.

Palavras-chave: Educação Artística; Investigação educativa

\section{ABSTRACT}

This article presents a review about the current state of art education theories and the relationships between arts education research and arts education practices.

Keywords: Art Education; Educational Research 
Desde un punto de vista epistemológico, nos dice Jorge González, la realidad no está estructurada, es estructurable; no está ordenada es ordenable. Y más adelante afirma que la realidad no solo es estructurable es estructurante. Por eso el conocer depende de la estructura del que conoce ${ }^{1}$. Indagar sobre el estado actual de las capacidades de investigación en Educación Artística y el modo en que se manifiestan en la práctica educativa diaria implica develar una red de relaciones. De esa red de relaciones entre educadores y educandos mediados por los contenidos sensibles de las artes, surgen los contextos de interacción a indagar que constituyen la realidad de las prácticas educativas.

De qué realidad parte el educador de arte de hoy, particularmente en Latinoamérica, el contexto que mejor conozco, en el ámbito del arte y de la educación y de qué modo queda determinada la investigación que se desgaja de ellos.

a. Las capacidades de investigación de los maestros y profesores de educación artística pasan primero por la preparación que posean en las artes y el nivel de actualidad y comprensión de los procesos simbólicos de su contemporaneidad. El educador, entonces, está retado a someterse a una educación permanente: el educador debe ser educado. Pero esto queda más en el plano de los retos que de los empeños o los logros.

b. Por lo general, el educador, en su formación y en sus "habitus", se queda varado en un canon de arte, cuando llega a alcanzarlo, que no supera lo ofrecido por las vanguardias históricas, los ismos iniciales del pasado siglo en Europa, luego encarnados en nuestra América y ligados a los movimientos de renovación político-social de la época: Revolución mexicana, reformas universitarias, creación de partidos políticos de izquierda, etc. De aquí que resulte, en el mejor de los casos, ser visto el arte básicamente como instrumento expresivo reflejo de circunstancias epocales.

${ }^{1}$ CF. González, Jorge (Coord.) (2007): Cibercultur@ e iniciación en la investigación. Consejo Nacional para la Cultura y las Artes, México D.F. c. Dentro de esos ismos se afilian más a aquella vertiente de realización plástica que no renuncia del todo a la representación figurativa y, en menor medida, a tendencias representativas vinculadas a las diversas realizaciones abstractas, sean estas geométricas o no; mucho menos aún a las operaciones dadaístas que le negaban preeminencia a la elaboración del objeto artístico y a su naturaleza visual y que van a derivar décadas después en diversas vertientes de arte desde el pop y los conceptualismos, donde la objetualidad singular y trascendental de lo artístico se echa abajo; hasta territorios de lo performántico y lo efímero, donde la dimensión de lo ecológico, lo etnográfico u otro referente disciplinar se constituye en herramienta de realización.

d. De las ideas de arte expuestas que asimilan los educadores como patrón se desgaja, a su vez, una idea de la realidad y de lo real, donde lo real y la realidad es aquello externo e independiente de los sujetos y donde la objetividad y lo objetivo se alzan como algo contrapuesto y exento de la mirada y la presencia contaminante de lo subjetivo.

e. La anterior presunción cimenta el criterio tradicional de la investigación centrado en el denominado Método científico; de donde lo hipotético deductivo y la experimentación resultan paradigmas de aplicación en todo empeño investigativo, asociados a ellos estarían los recursos estadísticos, en tanto que se fundan en la creencia de la fiabilidad objetiva de los números.

f. Por otra parte, los educadores carecen de un adecuado conocimiento de experiencias pasadas valiosas de otros educadores del arte en el contexto de su propio país o región y la investigación histórica sobre ese particular se muestra generalmente poco atendida y desarrollada, a partir de la engañosa creencia de que en esos ámbitos no hay experiencias propias significativas.

De lo citado se desprende que para conocer el desarrollo alcanzado en las capacidades investigativas en Educación Artística es central analizar qué modelos de arte son los que ganan espacio en la escuela y con qué tipos de comportamiento de producción y recepción de las artes se les asocia y el porqué las indagaciones de corte histórico son escasamente practicadas. A inicios de los 90 el teórico del arte Juan Acha había señalado que en América Latina re- 
sultaban dominantes determinadas falacias acerca del arte $^{2}$ , que coincidentemente eran, a su vez, dominantes en los discursos de los medios masivos y de la industria cultural y que se convertían en axiomas. Esto no significa, sin embargo, ningún juicio a priori negativo para la realidad cultural constituida por ellos.

Esas falacias se asentaban en la creencia del arte como belleza, como realismo fotográfico, como sentimiento o expresividad, como entretenimiento, como magia religiosa. A la par de estas se desprende a su vez una idea de los fines que mueven a los artistas y, en cierta medida, de las cualidades que deben poseer o de que deben estar dotados éstos. De acá luego se deducirían comportamientos recomendables como metas para la práctica educativa de la educación artística y de aquí, entonces como posible, lo que figuraría como asunto de investigación mediado por tales presunciones queda postergado por la misma razón que tales falacias, en tanto axiomas culturales, no se someten a cuestionamiento alguno, sino que se constituyen en comportamientos arropados por el hábito y el sentido común. Por lo mismo estas falacias se levantan como razones que hacen superflua la necesidad de la investigación.

El arte visto como belleza se asocia, por lo general, a un canon estético occidental y clásico. La enseñanza se ciñe por tanto a un modelo cultural definitivamente superado en nuestras prácticas simbólicas contemporáneas. El arte encarado como realidad fotográfica remite a una concepción reflexológica del arte, donde este resulta concebido como "espejo" de realidades y no como otra realidad. En vez de concebir que en el discurso del arte se construye un "algo" que resulta su realidad y que no remite como tal a una realidad externa que le sirve como modelo, sino que en el propio producto artístico se halla una nueva realidad fundada, aquello que Wolfang Iser denominó como la indeterminación de los textos ficcionales, pues ellos constituyen sus propios objetos y no copian algo que ya existe.

${ }^{2}$ Cf. Acha, Juan (1992): Introducción a la creatividad artística. Editorial Trillas, México D.F.
El arte asumido como sentimiento o expresividad privilegia solo en el discurso del arte lo afectivo en desmedro de otras funciones presentes en la producción artística. De igual manera la visión del arte reducido al placer del entretenimiento o a su vínculo con temas religiosos y al ideologema primario de las virtudes mágicas de ciertas imágenes, hace que la presencia del arte en la práctica educativa pierda todo su sentido formativo crítico y cultural.

Todo lo expuesto hasta aquí pudiera parecer demasiado genérico, si no lo vinculo con hechos concretos en el campo socialmente sancionado de las investigaciones. Cuando digo campo socialmente sancionado, estoy expresando con ello de que manera un conjunto de ideas dominantes sobre lo que es la investigación y lo científico gravitan alrededor de qué y cómo se investiga; lo que queda expresado con el término de "doxa", megasistema de información concretado en instituciones especializadas en la metabolización y elaboración permanente del discurso social de la ciencia y su diseminación en el cuerpo social todo. De ahí los esquemas dominantes de disposiciones cognitivas de acción, de percepción, de valoración que luego quedan sancionados en el discurso científico.

Partiré de experiencias personales, como tutor, jurado y oponente de tesis de licenciatura, de maestría y de doctorado en asuntos de educación artística, en ámbitos universitarios de mi país y de otros países latinoamericanos, donde se manifiestan evidencias de esa "doxa", y donde el emplazamiento crítico de ella debe conducir al reconocimiento de nuevos epistemes de investigación, con especial atención a los anteriores argumentos enumerados acerca del arte y de sus complejas realizaciones en la contemporaneidad.

Una de las primeras incongruencias a las que siempre me he enfrentado en estas funciones antes enumeradas, es sobre la concepción dominante de la Literatura en la práctica educativa en tanto disciplina del conocimiento de la lengua escrita desde su flanco preceptivo, normado, regularizado, historizante; pero escasamente desde la práctica heurística con la lengua, donde ésta como hecho vivo transcurre sin respetar apriorísticamente modelos de corrección lingüística. Como regla la Literatura nunca se la considera en los planes de estudio de formación primaria, media y media 
superior como materia de la Educación Artística, a pesar de ser por naturaleza arte de la palabra. Esto hace que a la hora de investigar sobre ella en la educación, se haga en olvido o postergación de esa razón de ser esencial.

De otra parte, encarar la Literatura en tanto arte no solo tiene implicaciones con respecto a su razón de ser, sino que en la misma medida en que se enfatiza tal razón, se propicia potenciar la influencia que por lo mismo puede alcanzar la Literatura en el ser de los estudiantes. Ese fue el problema central abordado cuando dirigí una tesis de maestría sobre la enseñanza de la Literatura desde un enfoque personológico $^{3}$. La tesista fue conducida por la naturaleza misma del ser artístico de lo literario, a reconocer y comprobar que ello solo podía lograrse con una enseñanza-aprendizaje de la literatura que cultivara y priorizara la comprensión estética y artística de la lengua escrita. De aquí luego derivé en otras tesis sobre la enseñanza de la Literatura, donde enfatizamos sobre los usos literarios de la literatura, en un caso desde la creación literaria de los propios estudiantes y en otro desde su recreación dramática ${ }^{4}$. Tanto en una como en otra investigación los resultados no pudieron ser más significativos y concluyentes más allá de los marcos mismos de lo indagado.

Diana explicita las fortalezas de su propuesta en términos que pudieran ser extendidos a otras áreas disciplinarias de la educación artística, cuando argumenta que:

"La propuesta procura que ya no se perciba la literatura como un producto ajeno que nunca podrá ser parte de quien la estudia, sino que defiende a la literatura como un hecho artístico-expresivo, nacido de la necesidad del hombre por devenir más. Por lo tanto, el aprendiz en la actualidad, debe emprender ese mismo viaje ontológico. La presente propuesta busca motivar al alumno a que sienta la

\footnotetext{
3 Cf. Ana Ma. García (1997): “Un modelo teórico para la enseñanza de la Literatura en la escuela cubana centrado en el componente axiológico". Facultad de Humanidades, Universidad de Ciencias Pedagógicas "Enrique José Varona", La Habana, Tesis de Maestría.

${ }^{4}$ Cf. Diana Sepúlveda (2001):"El aprendizaje de la literatura a nivel preparatoria, mediante la creación". Facultad de Artes Visuales, UANL, Monterrey, Tesis de Maestría; Yliana Iruegas (2007): “El aprendizaje de la literatura a través del drama". Facultad de Artes Visuales, UANL, Monterrey, Tesis de Maestría.
}

literatura como parte de sí mismo y de su cultura, para que pueda ser su propio recurso expresivo.

En los métodos tradicionales el maestro y el texto/contexto son considerados como información, y dentro del salón de clases son los únicos que comunican o emiten datos concretos. La actual propuesta es relevante ya que propone que el alumno también sea un emisor de opiniones, de análisis y de textos; adquiriendo así una comprensión única e individual, llevando un aprendizaje personalmente relevante. Mediante el ejercicio de dicho aprendizaje significativo, el alumno adquirirá un papel activo, en lugar de mantenerse en una posición pasiva donde no se involucra emocional ni intelectualmente. A través de dinámicas de análisis, que desarrollarán y comunicarán su pensamiento crítico, y ejercicios de escritura, que expondrán su creatividad e interioridad, esta propuesta busca transformar la mecánica tradicional del salón de clases.

El cambio que se propone es el conceptuar la literatura como una experiencia, como una expresión individual que manifieste la vida interior del alumno. Al expresar sus vivencias, sus referentes personales y su necesidad creativa, la motivación aumenta, y la disposición emotiva hacia la literatura es más positiva.

Además, al involucrar emocionalmente al estudiante, otro resultado es que el aprendizaje no es a corto plazo, sino que establece una huella duradera en el educando." (Sepúlveda, $2001,8)$

Otro tanto lograría Yliana Iruegas con su tesis sobre el aprendizaje de la Literatura a través del drama. Esta otra dimensión propiciaba también parejas resonancias y hacía a los alumnos, como en la anterior tesis, partícipes del alumbramiento de la literatura como arte literario. Los resultados académicos obtenidos por ambas profesoras con sus alumnos destacaron a nivel de todo México en las Preparatorias del Tecnológico de Monterrey, lo cual les ganó inmediata simpatía en los predios institucionales; pero por encima de todo estaría el reconocimiento que los propios alumnos le confirieron a tales experiencias vividas como momentos personales imborrables y la confesión íntima de los valores experimentados con la literatura. 
En las tesis señaladas de acuerdo con la naturaleza del objeto indagado -la literatura en tanto arte- se privilegiaron métodos de investigación como los grupos de discusión, la entrevista personalizada, el análisis de la producción textual de los alumnos. En especial el evidenciar la evolución de la investigación desde los testimonios escritos de los estudiantes, con la matizada gama de realizaciones obtenidas en un proceso que manifiesta contradicciones, zigzagueos y, al final, logros, permite reconocer la validez del arte en la educación como fundamento de una formación personalizada donde los estudiantes reconocen a través de las artes, a la par que cualidades del discurso simbólico en sus contextos de producción y recepción, un crecimiento interior decisivo.

Otra incongruencia que siempre saltó a la vista era la necesidad de la historia. Resulta imposible indagar si antes no reconocemos qué experiencias anteriores a las nuestras existieron, qué ideas nos antecedieron. Por eso cuando se fundó la Facultad de Educación Artística, en 1985, en La Habana, una de las vertientes dominantes de la investigación fue la histórica; pues resultaba desorientador avanzar hipótesis desde un sentido de "actualidad", si esa no se reconocía en posibles antecedentes del contexto y, claro, no bastaba con reconocer referente históricos genéricos ${ }^{5}$. Martín Barbero reconoce cómo vivimos una fuerte deshistorización de la sociedad en beneficio del presente y de su valorización absoluta, y señala lo que ello implica no sólo como una merma de horizontes de futuro, sino también una peligrosa pérdida de memoria. Pero aclara que su planteo de la historia no es ir/huir al pasado, sino asumir el pasado de que está hecho el presente. Se trataría de encontrar claves en el pasado para identificar y descifrar las encrucijadas del presente. Eso en el ámbito de la educación artística y de la investigación sobre ella es central.

En el reconocimiento de la urgencia por conocer el pasado se descubrió que, aunque en su momento hubo voces que insistían en destacar las diferencias en la formación de un profesional de las artes y de un educador, las coincidencias que podían develarse eran superiores. Quizá solo porque en

\footnotetext{
5 Especialmente por esos años el texto de Irena Wojnar (1961): Estética y Pedagogía. FCE, México; luego vendrían otros títulos y autores, de particular relieve las indagaciones históricas de Ana Mae Barbosa en Brasil.
}

la mirada académica dominante prevalecía un sentido de arte tradicional, residual diría Juan Acha, y en la visión de la gráfica infantil, de acuerdo a los nuevos tiempos, se respiraban los argumentos de una estética expresiva, era posible acatar distinciones tajantes, que el paso del tiempo atenuaría, en la misma medida que tales paradigmas se hicieran menos contrastantes y otros surgieran como modelos dominantes desde estéticas relacionales y posturas pedagógicas constructivistas.

Una concepción dominante de la investigación educativa centrada en el Método científico y lo hipotético deductivo, que privilegia como paradigma la aplicación del experimento pedagógico y las experiencias de contrastación desde variables claramente determinadas, sujetas a comprobación estadística como tendencia, llegan a nuestros días en las investigaciones de tesis de maestría o tesis doctorales en educación artística o en disciplinas afines. Por ejemplo, en una tesis dedicada al desarrollo de la creatividad en la apreciación de obras de arte y la producción plástica de niños de cinco y seis años, con un grupo de estudio de 15 niños, de una población total de 120 de un Círculo Infantil, se aplica la prueba de Mc Nemar para la valoración de un sistema de acciones externas controladas. Sin embargo, no creo que fuesen tales acciones externas "controladas" las protagonistas del desarrollo de la creatividad en la apreciación y la producción plástica, donde se dan cita los procesos pre-conscientes e inconscientes, combinados con lo consciente en diversos gradientes sensibles y donde la intuición, la introspección y lo axiológico alcanzan particular relieve. Con tal muestra lo apropiado era la aplicación del estudio biográfico y de casos, donde el principio de lo narrado prime como procedimiento de indagación. En otra tesis dedicada a indagar sobre la metodología de trabajo apropiada para desenvolver los talleres de apreciación/creación de teatro, con niños de 6 to. Grado, se emplean indicadores identificados con números y letras -A1, B1, C1 y así sucesivamente hasta las letras con número 10-, referidos a categorías como flexibilidad, originalidad u otros. Pero no hay anécdotas, no hay imágenes, no está ni la voz, ni el gesto del niño, tampoco su "mirada" sobre lo que ve representado. ¿̇mportará eso para validar la metodología? En sustitución de eso está el modo en que el educador califica manifestaciones del pensar, del sentir 
y del hacer. La metodología creo que tiene que ser comprobada por el binomio educador-educando y no solo por el educador. Freire dice: "El acto de enseñar vivido por el profesor o la profesora va desdoblándose, por parte de los educandos, en el acto de conocer lo enseñado6". Eso tiene que dejarse "ver". A través de la narración se devela lo que el niño descubre, lo que vivencia y a su través se muestran los logros alcanzados de una manera estética y orgánica con la naturaleza de lo indagado y tal narración debe revelarse desde lo escrito y desde las imágenes mismas. La narrativa constituye una importante forma de conocimiento y se revela como un eficaz instrumento de investigación a favor de la captación emocional y vívida de los hechos educativos (McEwan y Egan, 2005).

De aquí se desprende otra problemática, el protagonismo de la imagen como método de indagación para la educación artística es muy poco reconocido y se halla muy pobremente empleado en nuestra cultura logocéntrica de investigación? Pero esto no significa que cualquier tipo de imagen, como a veces simplemente se cree, sirva como método y exposición investigativas. La imagen ha de ser aquella que revele momentos de significación de lo indagado y que lo haga de manera que lo que manifieste en imagen difícilmente pueda ser sustituido por otras evidencias. Por lo común, la imagen cuando se la emplea ilustra solo desde una mirada ancilar y secundaria lo indagado, por lo mismo que no se sabe captar y reconocer en esa "captura" el componente de cognición insustituible que portan las imágenes. En el caso de la producción gráfica infantil la captación del proceso mismo de elaboración de las imágenes es un proceso de un sincretismo singular que no remite únicamente a lo iconográfico, sino a un complejo juego de dramatización donde junto a esto concurren las acciones corporales, las palabras.

\footnotetext{
${ }^{6}$ Cf. Pedagogía de la esperanza. Siglo XXI editores, México, 1996, p. 77.

7 Ya Margaret Mead había comprobado esto en carne propia en su labor como antropóloga. Cf. Margaret Mead (1994): Experiencias personales y científicas de una antropóloga. Ediciones Paidós, Barcelona. En un pasaje de este texto se lee: "Cuando planeamos nuestro trabajo de campo decidimos utilizar activamente el cine y la fotografía (...). La decisión que tomamos no parece muy trascendental hoy en día (...) Así tuvimos que esperar casi 25 años antes que nuestra investigación hiciese impacto en la disciplina antropológica" (p. 217).
}

En una tesis de maestría que dirigí hace cerca de dos años sobre la dinámica lúdica en la expresión visual y literaria infantil, se hizo evidente la necesidad de recurrir al registro fotográfico, al igual que a la complementación con el diario de experiencia y al coleccionamiento de los testimonios escritos y gráficos de los niños; fue precisamente desde la evidencia que brindaban tales documentos que se hizo plausible aplicar el análisis textual y con ello derivar en conclusiones de valoración sustentable y probatoria ${ }^{8}$.

La tesis de maestría de Ana Fabiola Medina dedicada a develar el problema de la dinámica lúdica manifiesta en la expresión gráfica y escrita de los niños, empleó con profusión las imágenes gráficas y las narraciones infantiles y de sus análisis contrastado con el de otros grupos de niños (de la propia ciudad de Monterrey o de otros países como Brasil o Dinamarca), el investigador arribó a la demostración de argumentos que de otro modo hubiesen quedado expuestos genéricamente y sin suficiente sustentación. Ana Fabiola expuso: "Como claro ejemplo tenemos que los niños del taller de juego expresivo-creador, al ser chicos de nivel socio económico medio-alto, registran en sus textos, vacaciones a playas turísticas, Disneylandia, Los Ángeles o Nueva York, También sus barcos pirata guardan mayor semejanza con un crucero turístico que con un antiguo galeón español, aun cuando probablemente los hayan visto en películas. Lógicamente, estas experiencias no se encuentran en los niños de los grupos de "Probaditas" quienes hacen mención de paseos a parque públicos o ríos. Al hacer esta comparación de ninguna manera se intenta menospreciar la calidad de la experiencia de uno u otro grupo, el contraste lo marca la situación socio-económica familiar. El entorno cultural necesariamente se verá reflejado en el desempeño creativo de los chicos, pasado por el filtro de su personalidad y de su capacidad expresiva, finalmente lo importante es que, si el niño ha decidido recordar el momento y plasmarlo en el papel, es porque ha tenido gran importancia para él. Igualmente, hay experiencias que comparten los niños del taller con los de los otros grupos, incluyendo a los pequeños del

\footnotetext{
${ }^{8}$ Cf. Ana Fabiola Medina (2008): “La dinámica lúdica en la propuesta visual y literaria infantil”, Facultad de Artes Visuales, UANL, Monterrey. Tesis de Maestría.
} 
municipio de General Treviño, hasta los brasileños y los daneses: todos relatan un partido de futbol con la misma intensidad" (Fabiola, 2008, 76). Cuando refiere al final del párrafo a ese sentido de intensidad, éste se deja "ver" en el cuerpo de la tesis ostensiblemente en imágenes gráficas y narraciones de los propios niños, y desde ellas es que se hace posible coincidir con sus argumentos.

La creatividad, tantas veces asociada a la Educación Artística, capacidad de posible desarrollo en todo ser humano, exige cultura y aprendizaje. Siempre será un reto pensar en cómo concebir tal aprendizaje e indagar sobre él. Como capacidad es un componente estructural de la personalidad. La capacidad creadora tiene componentes intelectuales cognoscitivos, afectivo- motivacionales y volitivos conductuales y todos ellos manifiestos en un campo cultural dado y evidenciados desde el ser total de los educandos a través de múltiples canales de cristalización. Estos componentes se manifiestan en procesos tanto conscientes como inconscientes y pre-conscientes -recordemos a L. Kubie o A. Erhenzweig. Theodule Ribot en su "Ensayo sobre la imaginación creadora", del cual partió Vigotsky en su Imaginación y creación en la edad infantil, advierte que la imaginación "va de adentro hacia fuera", está regulada por el mundo interno, lo cual no significaba para él que estuviese disociada del pensamiento, puesto que consideraba que "la imaginación funciona mediante la disociación y asociación del pensamiento". G. Bachelard afirma que, contrario a lo que comúnmente se piensa, la imaginación no es la facultad de formar imágenes, sino la facultad de deformar las imágenes suministradas por la percepción y, sobre todo, la facultad de librarnos de las imágenes primeras ${ }^{9}$. En las investigaciones de Educación Artística todo esto tiene que alcanzar un máximo de visibilidad para que los mecanismos de lo analógico, lo metafórico y lo interno puestos de manifiesto desde la voz y la mirada de los escolares -niños y adolescentes- resulten testimonios singulares de las potencialidades específicas que se desgajan de su aplicación dialógica y significativa.

En los ámbitos académicos de investigación en que usualmente me he movido he escuchado el argumento, a partir

\footnotetext{
${ }^{9}$ Cf. G. Bachelard (1993): El aire y los sueños. FCE, México, p. 9 y ss.
}

de un conjunto de autores, que "la creatividad comienza con la formación de una hipótesis"; pero esta creatividad está lejos de ser la artística. El artista no parte de hipótesis para demostrar nada. El artista, por el contrario, crea hipótesis, mundos posibles. Los niños a través de la educación artística pueden ejercitar con propiedad placentera esa cualidad. El método hipotético deductivo no es el propio del productor simbólico. Como dice Ernesto Sábato: “El lenguaje (el de la vida, no el de los matemáticos), ese otro lenguaje viviente que es el arte, el amor y la amistad, son todos intentos de reunión que el yo realiza desde su isla para trascender su soledad. Y esos intentos son posibles en tanto que sujeto a sujeto, no mediante los abstractos símbolos de la ciencia, sino mediante los concretos símbolos del arte, mediante el mito y la fantasía: universales concretos. Y la dialéctica de la existencia funciona de tal modo que tanto más alcanzamos al otro cuanto más ahondamos en nuestra propia subjetividad". ${ }^{10}$

Claro, en esta cita Sábato alude a un tipo de ciencia que aún no se ha abierto desde epistemes contemporáneos a una relación enteramente nueva sobre lo subjetivo y lo objetivo, que considere que las unidades de observación siempre han de estar compuestas, en última instancia, por "observables". Ya no más la concepción de sujetos marginados o suprimidos del acto de observación, sino la acción del conocimiento construida en la interacción y en la interpretación de sujetos sobre los objetos, donde ni uno, ni otro puedan existir por separado con lo que la observación sobre las cosas que se indagan se convierten por lo mismo en "observables". Maturana nos alecciona sobre esto cuando afirma que a la visión trascendental de la objetividad él opone la [objetividad]. Quizá por la implicación que en los discursos simbólicos contemporáneos alcanza lo cotidiano, lo multicultural, la presencia de las nuevas tecnologías y la gama de realizaciones de la industria cultural, esa [objetividad] se muestra doblemente orgánica en su aquí y en su ahora. Solo del descubrimiento concreto de esa realidad siempre plural y difusa donde toda objetividad queda mediada por los sujetos que la interpretan es que puede levantarse una

10 Cf. Ernesto Sábato (1991): El escritor y sus fantasmas. Seix Barral, Madrid, p.144. 
idea comprensiva del arte en la educación y los modos de indagar sobre ello.

La educación artística que ya habíamos anotado relacionada con las ideas que los educadores tengan del arte, deben tener como botón de referencia el conjunto de cualidades que apunta Brea ${ }^{11}$ de las prácticas artísticas del siglo XXI, entre las cuales podrían enumerarse: el reconocimiento de que no existen más los artistas, ni los autores, que solo hay productores, ellos en sí mismos productos; que el trabajo (intelectual, inmaterial, simbólico) nos produce; que la figura del artista vive en tiempo prestado; que no existen obras artísticas, sino trabajos y prácticas artísticas; que la producción artística no debe confundirse con el objeto o la forma. Cada una de tales afirmaciones supone el reconocimiento de un cambio de episteme de lo simbólico y de su producción; también lo será de la educación y de las investigaciones que se deriven de hacer posible ese reto.

Todo lo expresado, sin embargo, no es más que expresión de una ideología de vanguardia que está lejos del pensamiento dominante en los predios educacionales, entre otras cosas, por el natural desfase que siempre opera a nivel social entre producción y recepción simbólicas ${ }^{12}$. Analizar el predominio del nivel conceptual, como característica del arte de hoy, y su relación con el mundo de la sensibilidad cotidiana y el ámbito de lo cotidiano, es obra de un proceso cultural y educativo de largo y sostenido aliento y no obra inmediata y fácil. Esto entraña, entre otros, el entendimiento de cómo la acción de "ver" como acción natural es extraordinariamente limitada e idea falaz, por tanto de las exigencias de acometer ese "ver" desde la comprensión de su carácter cultural, sujeto a entrenamiento, a la educación de todos nuestros analizadores. ${ }^{13}$

\footnotetext{
11 Cf. José Luis Brea (2004): “Apéndice. Redefinición de las prácticas artísticas (siglo21)", en: EL TERCER UMBRAL. Estatuto de las prácticas artísticas en la era del capitalismo cultural. Cendeac, Murcia, pp. 155 - 166.

12 Ya Dewey se refería a ello cuando señalaba la naturaleza predictiva del arte, en su El arte como experiencia, o Eco cuando afirmaba en su Obra abierta acerca de la interlocución que organizaba el arte con los espectadores del mañana.

13 Pierre Bourdieu desnuda tales relaciones de toda mistificación encubridora en "Elementos de una teoría sociológica de la percepción artística", en: Image 1. Teoría francesa y francófona del lenguaje visual y pictórico. Criterios, La Habana, 2002, pp. 189 - 221.
}

A la par lo expresado se vincula con el instrumental de análisis con el cual pueden ser comprendidas y juzgadas las producciones simbólicas de hoy día. Ya Gillo Dorfles advertía en su Devenir de la crítica cómo los críticos estaban imposibilitados de comprender el discurso artístico contemporáneo si se remitían a una historia del arte centrada en la técnica, las categorías estéticas tradicionales o peculiaridades gestálticas cuando los productos culturales tienen sus principios de construcción en otros epistemes. ${ }^{14}$

Esto significa también pareja orientación de cambio en la educación artística, lo cual supone que en vez de concebirla como materia de preservación elitista de la tradición y la alta cultura, alcance a convertirse en lugar de puesta en escena de lo cotidiano, de espacio para los medios masivos y para lo espectacular; en la asunción de una nueva concepción de relación entre el hacer visual de hoy en búsqueda de experiencias instantáneas e incitantes y la configuración cultural de un nuevo tipo de espectador de la cultura artística.

En nuestra realidad cultural latinoamericana híbrida y mixturada con identidades donde los imaginarios populares y electrónicos se mezclan en los relatos audiovisuales, donde se mestizan cultura oral e imaginerías de la visualidad electrónica. La educación artística se manifiesta como espacio de dilución de lo heterogéneo y diverso, de lo conflictivo, en pos de una pretendida unidad. Con un patrimonio artístico conservado ritualmente, como algo dado, no discutible, ni revisable; difundido verticalmente, no vinculado a la cotidianidad, ni a su uso social; con una concepción culturalista como evasión hacia un imaginario pasado glorioso, la educación artística queda paralizada como agente de cambio. Por eso ese patrimonio así concebido debe ser emplazado críticamente desde la investigación.

Será, entonces, central para sus argumentos de cambio indagar cómo convertir a la educación artística en espacio de diálogo con las culturas del presente y del mundo y el desbordar la frontera entre las artes, lo cual supone acercarse a ellas con "sentimiento de provisionalidad", con valoración de lo instantáneo, breve, superficial, frívolo; con genuinas

14 Cf. Gillo Dorfles (1979): El devenir de la crítica. Espasa - Calpe, Madrid, pp. 26 y ss. 
experiencias de fugacidad y fragmentación del mundo, articulador de pasado con futuro, memoria con experimentación, de resistencia contra la superioridad de unas culturas sobre otras; buscador de voces excluidas, de alteridades y residuos. Pero para alcanzar esto el propio educador ha de "educarse" y ha de someter su accionar educativo a la mirada cuestionadora de la investigación.

Si contemporáneamente el arte como máquina de sentido debe ser un instrumento cuestionador de realidades, a la par que brindar nuevos modos de ver, sentir, experimentar y conocer el mundo, más allá de las evidencias primeras, de la epidermis de las cosas y de los hábitos perceptivos donde se adormecen todas las inquietudes; la educación artística debe preparar a niños y jóvenes para comprender y vivir eso con todo su cuerpo. Lo cual obliga a indagar cómo el ojo se salta el muro de lo banal, de lo consabido, de lo inerte y funda realidades inquisitivas, más humanas.

La Habana, marzo del 2010.

\section{REFERENCIAS BIBLIOGRÁFICAS}

ACHA, Juan. (1992): Introducción a la creatividad artística. Editorial Trillas, México D.F

BACHELARD , G. (1993): El aire y los sueños. FCE, México, p. 9.

BOURDIEU, P. ( 2002): “Elementos de una teoría sociológica de la percepción artística", en: Image 1. Teoría francesa y francófona del lenguaje visual y pictórico. Criterios, La Habana, pp. $189-221$.

FREIRE, P. ( 1996): Pedagogía de la esperanza. Siglo XXI editores, México, p. 77.

GARCíA, Ana Ma.(1997): “Un modelo teórico para la enseñanza de la Literatura en la escuela cubana centrado en el componente axiológico". Facultad de Humanidades, Universidad de Ciencias Pedagógicas "Enrique José Varona", La Habana, Tesis de Maestría.

GONZÁLEZ, Jorge (Coord.) (2007): Cibercultur@ e iniciación en la investigación. Consejo Nacional para la Cultura y las Artes, México D.F.

IRUEGAS, Yliana (2007): "El aprendizaje de la literatura a través del drama". Facultad de Artes Visuales, UANL, Monterrey, Tesis de Maestría.

MEAD , M. (1994): Experiencias personales y científicas de una antropóloga. Ediciones Paidós, Barcelona. p. 217.

MEDINA, Ana Fabiola (2008): “La dinámica lúdica en la propuesta visual y literaria infantil", Facultad de Artes Visuales, UANL, Monterrey. Tesis de Maestría.

SÁBATO, E. (1991): El escritor y sus fantasmas. Seix Barral, Madrid, p.144.
SEPÚLVEDA, Diana (2001):"El aprendizaje de la literatura a nivel preparatoria, mediante la creación". Facultad de Artes Visuales, UANL, Monterrey, Tesis de Maestría.

WOJNAR, I. (1961): Estética y Pedagogía. FCE, México. 